\title{
Asymmetric C-H Alkylation of Fluoroarenes with Alkenes via Nickel/NHC Catalysis
}

\section{Category}

Metals in Synthesis

\section{Key words}

hydroarylation

C-H alkylation

chiral NHC ligands

fluoroarenes

nickel catalysis

\section{Syniact
of the}

Significance: The authors demonstrate an unprecedented catalytic enantioselective $\mathrm{C}-\mathrm{H}$ alkylation of polyfluoroarenes. The annulation displayed complete endo selectivity, with exclusive $\mathrm{C}-\mathrm{H}$ over $\mathrm{C}-\mathrm{F}$ activation, and excellent enantioselectivity.
Comment: In addition to conferring excellent enantioselectivity, the use of the rather bulky chiral $\mathrm{N}$-heterocyclic carbene ligand for the nickel catalyst prevented any competition from $\mathrm{C}-\mathrm{F}$ activation; as such, there was complete chemo- and regioselectivity. 